\title{
Ciencia de la ficción: un repaso psicológico de sus efectos prosociales
}

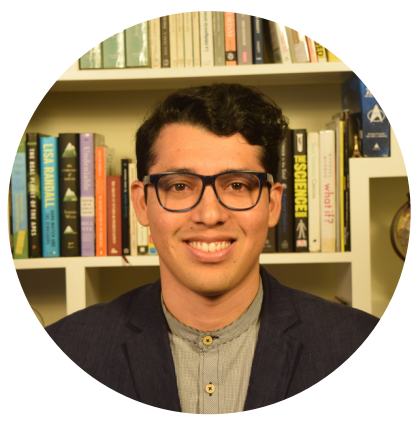

\section{FABRIZIO LÓPEZ DE POMAR ID https://orcid.org/0000-0002-9972-8987}

Licenciado en psicología por la Universidad de Lima. Miembro e investigador de la Sociedad Secular Humanista del Perú (SSH) y del Instituto de Estudios Transhumanistas (IET). Miembro del Consejo Editorial del Fondo Editorial de la Sociedad Secular Humanista del Perú.

$\checkmark$ lopezdepomar.fabrizio@ssh.org.pe (0) @beingthebridge

Resumen. El presente texto expone hallazgos que la ciencia ha ofrecido en los años recientes sobre los efectos psicológicos que tiene leer literatura de ficción, en comparación con no leerla. Se acuña el concepto de "ciencia fricción" por las nuevas implicancias que surgen al escribir el género de ciencia ficción durante la Cuarta Revolución Industrial. El artículo tiene como objetivo revaluar la importancia de leer y escribir en dicho género literario no solo como entretenimiento sino como un entrenamiento psicológico que nos prepare para las nuevas vivencias humanas que las tecnologías están propiciando.

Palabras clave: ciencia ficción, psicología, mejoramiento moral, Cuarta Revolución Industrial

\section{Introducción}

¿De cuántas maneras podemos mejorar la sociedad? Dentro del conjunto de posibles respuestas, deseo enfocarme esta vez en la literatura, especialmente la de ficción. ¿Puede la lectura de relatos ficticios contribuir al cultivo de una mejor sociedad? ¿Los textos de ficción están para entretenernos o realmente nos preparan para vivir? En este breve texto haré un repaso de los efectos psicológicos que este género tiene en sus lectores. Planteo este análisis para reconsiderar su valor, pero también por la importancia de escribir dentro de este género, pues como veremos, es posible que en él se esté contribuyendo de alguna manera a mejorar ciertas condiciones psicológicas que puedan prepararnos para futuras experiencias, y de esa forma, sumarse a la mejora continua de la sociedad.

Si pensamos en algunos cuentos o novelas, quizás recordemos ciertos pasajes, personajes, o expresiones que en determinadas circunstancias se grabaron en nosotros de manera indeleble. Los textos de ficción nos invitan a vivir historias que muy probablemente no hemos vivido, ni viviremos. Sin embargo, estos viajes ficticios parecen modificar nuestra psicología en la realidad. A continuación, una breve exposición de la ciencia atrás de la literatura de ficción y reflexiones en torno a los desafíos y compromisos que significa escribir ficción en esta Cuarta Revolución Industrial. Se acuña la expresión "ciencia-fricción" para hacer alusión a estos nuevos desafíos que genera la ciencia y su tecnología para el equilibrio social.

\section{La psicología de la ciencia ficción}

Contarnos historias es una de esas capacidades que, prácticamente, adquirimos como especie desde la cuna. Usamos los relatos para darle sentido al mundo, para transmitir mensajes a las generaciones, para crear y mantener comunidades, y para aprender sobre nosotros y los otros. La literatura, en especial la de ficción, ha sabido capitalizar este mecanismo connatural, y con la creación de situaciones ficticias, nos llevan a simular mundos y vivencias que transforman nuestras habilidades sociocognitivas. Diversos trabajos científicos vienen demostrando que las personas que leen ficción, en comparación de aquellas que no lo hacen, tienen una mayor estimulación en la capacidad para ponerse en el lugar de las otras per- 
sonas, aquello que suele llamarse en psicología teoría de la mente (Black \& Barnes, 2015; Oatley, 2016).

Los trabajos experimentales demuestran que los circuitos cerebrales que procesan la información social en interacciones reales, se ejercitan también cuando se está leyendo ficción (Kidd \& Castano, 2013; Kidd et al., 2016; Mar, 2011; Tamir et al., 2015). Esta experiencia inmersiva permite que el lector se ponga en la piel del personaje $y$, como han evidenciado los estudios, los lleva posteriormente a desempeñarse mejor en tareas que requieren una buena inferencia social y capacidad empática (Mar \& Oatley, 2008). En otras palabras, están mejorando su capacidad de empatizar e imaginar lo que ocurre en la mente de las otras personas. Si bien la capacidad empática no solo se desarrolla mediante la lectura, y si bien se puede ser una persona con niveles de empatía muy superior al promedio sin haber leído novelas o cuentos clásicos, lo que estos trabajos académicos demuestran es que leer ficción no es una actividad solamente de ocio, de puro entretenimiento, sino que efectivamente sus lectores están entrenando sus capacidades sociocognitivas, y a esas conclusiones llegan también los meta-análisis al respecto (Dodell-Feder \& Tamir, 2018; Mumper \& Gerrig, 2017).

\section{La ciencia-fricción en la Cuarta Revolución Industrial}

La novedad que el avance tecnológico trae esta vez para la especie humana es que su poder nos está haciendo caminar por un precipicio existencial, como menciona Toby Ord (2020). En ese sentido, las decisiones que tomamos de manera individual $y$ colectiva, se hacen más determinantes: un pensamiento en falso y podría costarnos muy caro. Como señalaron Persson y Savulescu (2008), cada vez más incrementa el riesgo de poner mucho poder tecnológico al alcance de personas que poco o nada les importa ayudar a la sociedad, sino todo lo contrario. Es por eso que dichos autores hacen un llamado a acompañar nuestro progreso tecnocientífico con un mejoramiento moral. Este escenario nos permite darnos cuenta que se hace vital reunir todos los medios posibles para mejorar nuestra constitución psicológica. Uno de esos medios es el arte de escribir ficción.

Se le atribuye a Ray Bradbury describir un texto de fantasía como el arte de lo imposible, y uno de ciencia ficción como el arte de lo posible. ¿Cuáles son estos nuevos escenarios posibles que nos esperan? ¿Qué desafíos se presentan para este arte cuando se reconocen las tecnologías de esta Cuarta Revolución Industrial (4RI)? Algunos autores han señalado que tenemos limitaciones consustanciales para empatizar con personas lejanas en el tiempo y espacio, en donde nuestra imaginación, por muy potente que sea, aún nos dificulta el poder preocuparnos en afinar nuestros juicios morales (Ballesteros, 2020). Aquí es donde la ciencia ficción tiene un rol importante, pero debe prestar atención a los trabajos empíricos que demuestran que las ficciones con escenarios más reales, más cercanos al lector, permiten estimular más la empatía pues logra conectar más con las vivencias de los personajes, en comparación a ficciones futuristas (Pino \& Mazza, 2016).

Dicho de otra forma, para que la ciencia ficción continúe mejorando el desarrollo de las habilidades sociocognitivas como la empatía, debe enfatizar los posibles nuevos problemas emocionales que traerá el futuro, poner a los lectores en la piel de los humanos del mañana. Por ejemplo: ¿Qué preocupaciones tendrá una persona que está cumpliendo 200 años de vida? ¿Cómo será un juicio cuando los derechos humanos coexistan con los derechos posthumanos? ¿Se le puede acusar de infidelidad por tener experiencias sexuales con un robot humanoide? ¿Cuáles serán los nuevos hashtags de activismo social en el futuro?

En conclusión, las investigaciones psicológicas nos permiten reconocer que los textos de ficción mejoran las capacidades sociocognitivas en comparación a otros tipos de textos. En ese sentido, se reconoce que el género de ficción es una vía más para mejorar nuestros juicios morales en una época donde las tecnologías de la 4RI exigen de nuestra parte una mayor sabiduría. La ciencia ficción que hoy se escriba desde esta $4 \mathrm{RI}$ sin duda será un género con un compromiso renovado, en donde muy probablemente lo estemos leyendo no solo como entretenimiento, sino como entrenamiento para un futuro que en estos mismos momentos estamos construyendo.

\section{Referencias}

Ballesteros, V. (2020). De Günther Anders al transhumanismo: la obsolencia del ser humano y la mejora moral. ISEGORÍA. Revista de Filosofía Moral y Política, 63, 289-310. https://doi.org/10.1016/isegoria.2020.063.01 
Black, J. E., \& Barnes, J. L. (2015). The effects of reading material on social and non-social cognition. Poetics, 52, 32-43. https://doi.org/10.1016/j.poetic.2015.07.001

Dodell-Feder, D., \& Tamir, D. I. (2018). Fiction reading has a small positive impact on social cognition: A meta-analysis. Journal of Experimental Psychology: General, 147(11), 1713-1727. https://doi.org/10.1037/xge0000395

Kidd, D., \& Castano, E. (2013). Reading Literary Fiction Improves Theory of Mind. Science, 342(6156), 377-380. https://doi.org/10.1126/science.1239918

Kidd, D., Ongis, M., \& Castano, E. (2016). On literary fiction and its effects on theory of mind. Scientific Study of Literature, 6(1), 4258. https://doi.org/10.1075/ssol.6.1.04kid

Mar, R., \& Oatley, K. (2008). The function of fiction is the abstraction and simulation of social experience. Perspective on Psychological Science, 3(3), 173-192. https://doi.org/10.1111/j.1745-6924.2008.00073.x

Mar, R. A. (2011). The Neural Bases of Social Cognition and Story Comprehension. Annual Review of Psychology, 62(1), 103-134. https://doi.org/10.1146/annurev-psych-120709-145406
Mumper, M. L., \& Gerrig, R. J. (2017). Leisure reading and social cognition: A meta-analysis. Psychology of Aesthetics, Creativity, and the Arts, 11(1), 109-120. https://doi.org/10.1037/aca0000089

Oatley, K. (2016). Fiction: Simulation of Social Worlds. Trends in Cognitive Sciences, 20(8), 618-628. https://doi.org/10.1016/j.tics.2016.06.002

Ord, T. (2020). The precipice. Existencial risk and the future of humanity. Hachette Books.

Persson, I., \& Savulescu, J. (2008). The perils of cognitive enhancement and the urgent imperative to enhance the moral character of humanity. Journal of applied philosophy, 25(3), 162177.

Pino, M. C., \& Mazza, M. (2016). The Use of "Literary Fiction" to Promote Mentalizing Ability. PLOS ONE, 11(8), e0160254. https://doi.org/10.1371/journal.pone.0160254

Tamir, D. I., Bricker, A. B., Dodell-Feder, D., \& Mitchell, J. P. (2015). Reading fiction and reading minds: the role of simulation in the default network. Social Cognitive and Affective Neuroscience, 11(2), 215-224. https://doi.org/10.1093/scan/nsv114

\section{Cómo citar este artículo:}

López De Pomar, F. (2021). Ciencia de la ficción: un repaso psicológico de sus efectos prosociales. Futuro Hoy, 2(3), 17-19. https://doi.org/10.52749/fh.v2i3.2

Esta obra está bajo licencia internacional Creative Commons 4.0 Reconocimiento 4.0. 